\title{
Patterns of Neurological Involvement in Relation to Chronic And/Or Recurrent Erythema Nodosum Leprosum
}

\author{
A. B. A. KARAT \\ Consultant Physician \\ M. A. FURNESS \\ Chief Physiotherapist \\ Mrs. S. KARAT \\ Consultant Surgeon \\ Schieffelin Leprosy Research Sanatorium, Karigiri, S. India \\ P. S. S. RAO \\ Reader in Bio-statistics, Christian Medical College and Hospital \\ Vellore 4, North Arcot District, S. India
}

\begin{abstract}
Comparative tests of the motor and sensory functions of 3 peripheral nerves, ulnar, median, and lateral popliteal, in leprosy patients with and without ery thema nodosum leprosum (ENL), revealed much greater loss of peripheral nerve function, particularly sensory function, in the patients with recurrent or chronic ENL than in those without ENL. The pathogenesis of the phenomenon is discussed.
\end{abstract}

Erythema nodosum leprosum (ENL) is a serious complication occurring during the clinical course of bacillated forms of leprosy, most commonly in lepromatous leprosy. Both the pathogenesis and clinical significance of ENL are ill-understood. The Committee on Classification at Madrid Congress (1953) suggested that "erythema nodosum leprosum is usually of good prognostic value". Wolcott (1947) presented evidence which demonstrated that there is a relative delay in clearance of bacilli in the "reaction group" who tend to take longer to become negative. He states: "We see clear evidence that erythema nodosum leprosum is detrimental to the patient". This view is also supported by Davison and Kooij (1957). These studies on the effect of ENL on the course of the disease have been mainly concerned with the bacteriological aspects of leprosy and make no reference to the neurological status of the patients following recurrent episodes of reaction.
It is generally accepted that ENL is accompanied by an acute inflammatory process occurring in tissues in which there are lepra bacilli (Ridley, 1960). Since the major target tissue in leprosy is the nerve, it would appear probable that this "reaction" could adversely affect peripheral nerves.

In order to test this hypothesis, therefore, a study of peripheral nerve functions was carried out in 33 patients with recurrent ENL and in a second group of patients with lepromatous leprosy but without ENL or acute neuritis who were receiving regular treatment with DDS, and who served as a control.

\section{MATERIAL AND METHODS}

In all, 66 ulnar, 66 median and 66 lateral popliteal nerves in 33 adult patients with a history of recurrent and/or chronic ENL were studied. All the patients had lepromatous leprosy with a history of 6 or more episodes of ENI, the maximum number of episodes being 
40 and the average 10 . Among this group, acute painful neuritis occurred at the time of ENL with a frequency varying from nil to 18 times, and an average of 4 episodes over a 36-month period. These patients were admitted to the Schieffelin Leprosy Research Sanatorium between 1964 and 1967 for treatment of "reaction" and were followed up for a minimum period of one year. These 33 patients were matched with the control group in relation to age, sex, duration of the disease and bacterial index (B.I.). In all cases peripheral nerve function was tested by (a) manual muscle tests, using the Medical Research Council grading scale; and $(b)$ charting of sensory areas in the upper and lower limbs, using No. 5 nylon-thread applicators.

Patients in the ENL group were available for more intensive study of peripheral nerve function as they were admitted to hospital during periods of "reaction". Peripheral nerve integrity was therefore further assessed in these patients on the basis of strength duration curves which were recorded at 3-month intervals, using a RAF-type II electronic stimulator.

During the acute phases of exacerbation of ENL and acute painful neuritis specific antileprosy treatment was stopped and anti. inflammatory drugs such as prednisolone, chloroquine, and parenteral antimony were given to control the reaction. Specific therapy was resumed when the entire reactive process was under control, usually 6 to 12 weeks after the acute episode.

\section{RESULTS}

Peripheral nerve function as recorded by manual muscle tests on the muscles supplied by the ulnar, median, and lateral popliteal nerves showed that there was a significant difference between the ENL group and the control group.

Thus, deterioration in function was observed in 12 ulnar nerves out of a total of 66 in the ENL group $(18 \%)$, whereas in the control group only 3 nerves $(4.5 \%)$ appeared to be adversely affected.

In regard to the median nerve, 6 out of 66
$(9 \%)$ deteriorated in the ENL group and no damage was recorded in the control group; while deterioration in the lateral popliteal nerve was observed in 5 out of $66(7.5 \%)$ and 1 out of $66(1.5 \%)$ in the ENL and control groups respectively (see Table 1).

TABLE 1

Peripheral nerve function

\begin{tabular}{lrrrrr}
\hline & \multicolumn{3}{c}{$\begin{array}{c}\text { ENL group } \\
\text { No. } \\
\text { Nerve }\end{array}$} & No. & \multicolumn{3}{c}{$\begin{array}{c}\text { Control group } \\
\text { No. } \\
\text { affected }\end{array}$} & $\%$ & $\%$ \\
\hline Ulnar & 66 & 12 & 18 & 3 & 4.5 \\
Median & 66 & 6 & 9 & 0 & - \\
Lateral popliteal & 66 & 5 & 7.5 & 1 & 1.5 \\
\hline
\end{tabular}

The greatest deficit in motor function was recorded in the ulnar nerve in both the ENL $(18 \%)$ and non-ENL groups and was statistically significant.

Progressive loss of sensory function as recorded by increase in the area of anaesthesia in the limbs was much more frequent and significant than the changes recorded in motor power by the manual muscle tests. Thus,

'TABLE 2

Increase in anaesthesia in 66 upper and lower limbs

\begin{tabular}{cccccccc}
\hline & \multicolumn{3}{c}{ Upper limb } & \multicolumn{4}{c}{ Lower limb } \\
ENL group & Control group & \multicolumn{2}{c}{ ENL } & group & Control group \\
No. & $\%$ & No. & $\%$ & No. & $\%$ & No. & $\%$ \\
\hline 51 & 76.5 & 7 & 10.5 & 52 & 78 & 8 & 12 \\
\hline
\end{tabular}

51 patients out of a total of $66(76.5 \%)$ showed an increase in area of anaesthesia in the upper limb in the ENL group as compared with 7 out of $66(10.5 \%)$ in the control group, while in the lower limb 52 out of $66(78 \%)$ showed an increase in the area of anaesthesia in the ENL group as compared with 8 out of $66(12 \%)$ in the control group (Fig. 1).

Strength duration curves recorded for the ENL group showed deterioration of nerve function in a slightly larger proportion of the patients than was recorded by the manual muscle test (Table 3). 


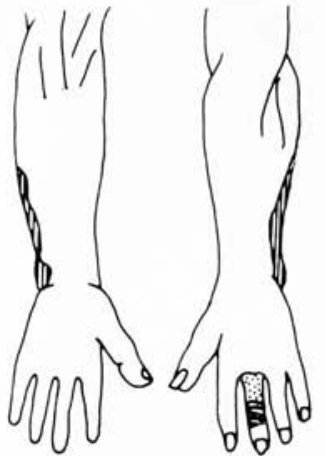

13 June 1967

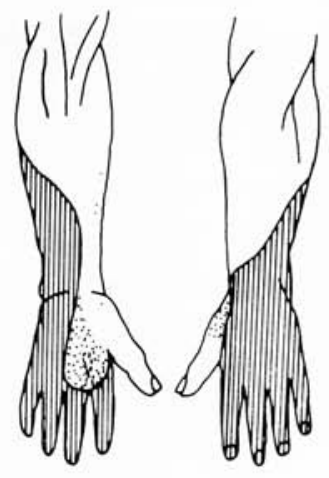

8 January 1968 (a)

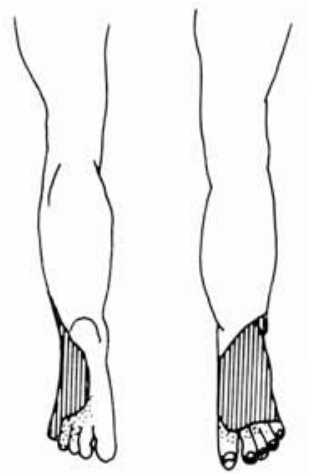

25 October 1965

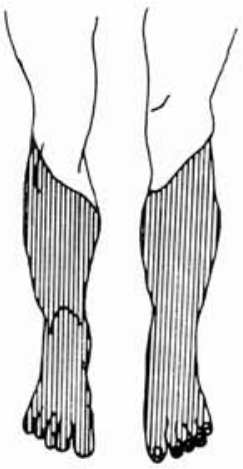

25 August 1968 (b)

FIG. I

Worsening of peripheral sensory loss $(a)$ in left arm and $(b)$ in left leg in patients with recurrent erythema nodosum leprosum is shown; shaded portions, areas anaesthetic to No. 5 nylon; stippled portions, area showing mis-reference.

TABLE 3

Deterioration in ENL group - strength duration curves (S.D.) and manual muscle tests (M.M.)

\begin{tabular}{lcc}
\hline \multicolumn{1}{c}{ Nerve } & S.I). curve & M.M. test \\
\hline Ulnar & $19.5 \%$ & $18 \%$ \\
Median & $15.5 \%$ & $9 \%$ \\
Lateral popliteal & $10.5 \%$ & $7.5 \%$
\end{tabular}

\section{DISCUSSION}

From the data presented it appears obvious that, on the whole, erythema nodosum leprosum adversely affects peripheral nerve function, both motor and sensory. There was no direct correlation between any of the various antiinflammatory drugs used in the ENL group to control the "reaction" and the change in nerve function. The serial strength-duration curves obtained from the patients in the ENL group appeared to be a reliable, objective method of detecting neurological deficit before clinical evidence of muscle weakness became apparent.

The exact pathophysiological process which results in the deterioration of nerve function is not clear. It is likely that during the ENL episode there occurs an acute inflammatory exudate in the nerve similar to that in the skin lesions of ENL (Job and Bhaktaviziam, 1967) and in the joints (Karat et al., 1967). The resultant oedema may cause neuropraxia in the acute phase followed by healing by fibrosis and scarring, which may contribute to destruction of nerve fibres and loss of nerve function. In a significant number of cases, the inflammatory response in the nerve may be very intense and may progress to abscess formation (ENL lesion of nerves) and destruction of nerve fibres. Though such a nerve lesion in lepromatous leprosy is thought to be uncommon, at the Schieffelin Leprosy Research Sanatorium during the last 6 months we have demonstrated such an abscess in 4 nerves in patients with lepromatous leprosy in reaction both at operation and by histological examination of the specimens of nerve obtained at surgery out of the 7 randomly explored, painfully enlarged, nerves during "reaction" (Figs 2 and 3). Clinically, there was a close relationship between abrupt onset of painful swelling of the ulnar, median or lateral popliteal nerves during ENL and the occurrence of "nerve abscess" in this group.

We have also observed a "vasculitis" of smaller blood vessels during severe reactions and confirmed this by histological examination. Typically there is proliferation of the endothelium, along with infiltration of all coats of the vessels with polymorph leukocytes. The endothelial cells are packed with large numbers of acid-fast bacilli. Vasculitis of this kind involving the vasa nervorum may cause 


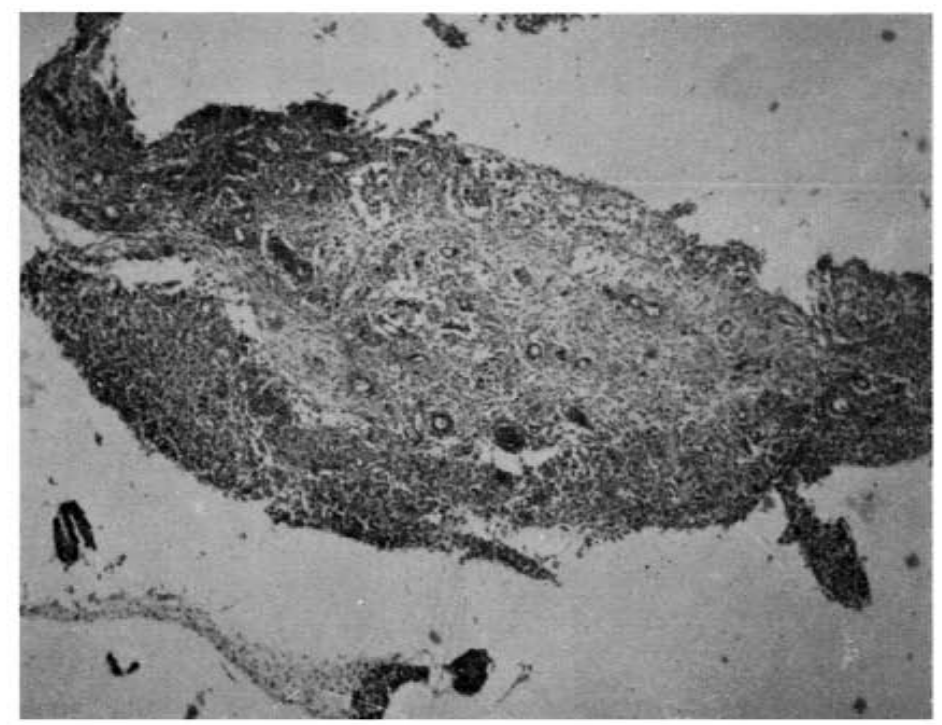

FIG. 2

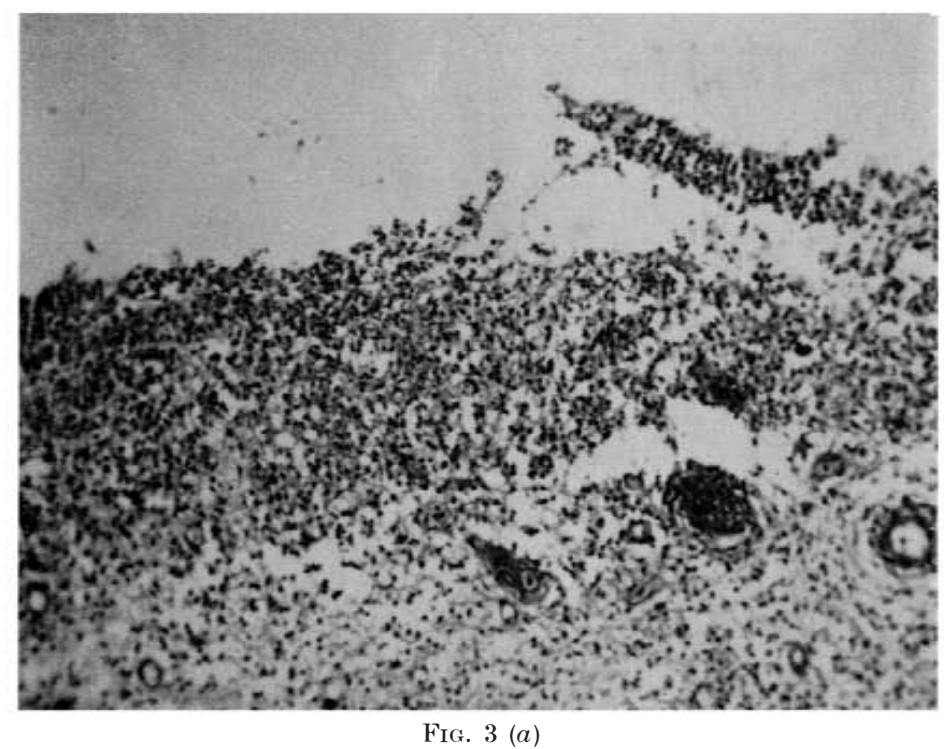

FIG. 2

Photomicrograph to show nerve abscess $(\mathrm{H} \& \mathrm{E} \times 30)$.
FIG. 3
Photomicrograph to show acute inflammatory
exudate consisting of polymorphs and macrophages
$((a) \mathrm{H} \& \mathrm{E} \times 120 ;((b) \mathrm{H} \& \mathrm{E} \times 400)$.

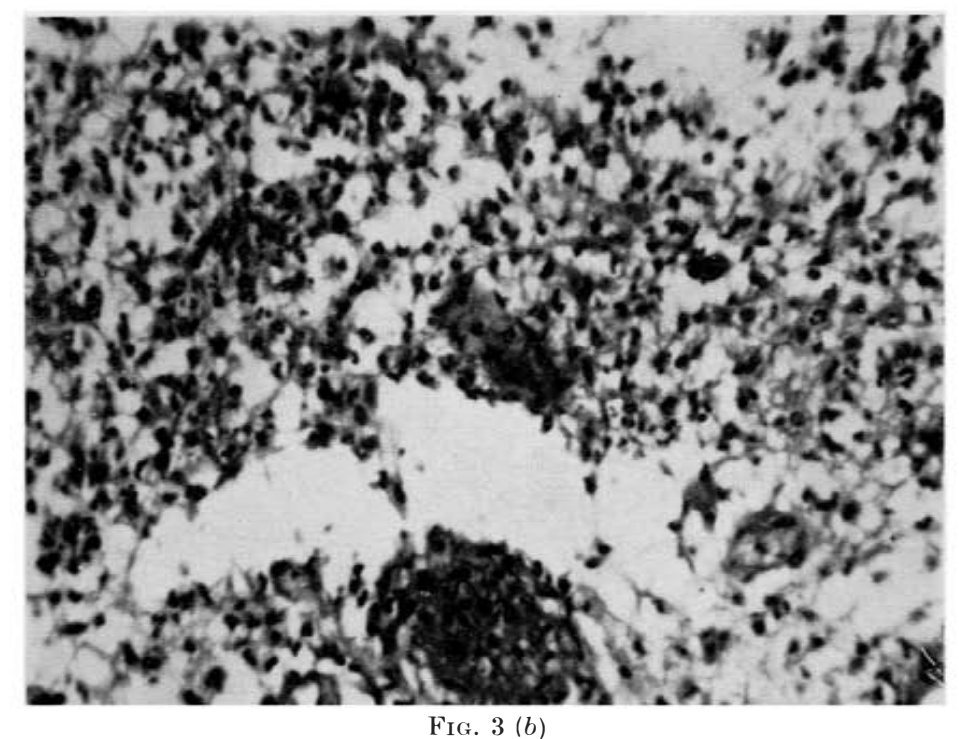


diminution of the blood supply to the nerve and consequent nerve damage.

Considerable data have been presented to suggest the possibility of an antigen-antibody reaction of hypersensitivity type or autoimmune type as one of the aetiological factors in the pathogenesis of "reaction" in leprosy (Ingram and Brain, 1957; Ridley, 1960). It is conceivable that the peripheral nerves, being the "target tissue" in lepromatous leprosy, may participate in this type of immunological reaction, to the detriment of the integrity of their function.

\section{SUMMARY}

In 33 patients with recurrent or chronic ENL a study of the ulnar, median and lateral popliteal nerves showed statistically significant deterioration in their motor and sensory function when compared with that in a carefully matched group of patients who did not develop ENL and were receiving regular, continuous treatment with DJ)S. Deterioration in sensory function in these patients was more marked than deterioration in motor power as recorded by the manual muscle test.

The pathogenesis of the production of nerve deficit in patients with recurrent reaction is discussed.

\section{ACKNOWLEDGEMENTS}

We are grateful for technical assistance by Mr. S. Jesudoss, for photomicrographs by Dr. Anand Date and for photographs by $\mathrm{Mr}$. Ebenezer, both of Christian Medical College \& Hospital, Vellore; and for secretarial assistance by Mrs. L. Furness.

\section{REFERENCES}

DAVISON, A. R. and KoolJ, R. (1957). Is erythema nodosum leprosum a favourable occurrence? Int. .J. Lepr. 25, 91.

INGRAM, J. T. and BRAIN, R. T. (1957). Sequeira's Diseases of the Skin, 6th ed., p. 276. London: Churchill.

JOB, C. K. and BHAktaviziam, c. (1967). Nerve abscess in lepromatous leprosy-report of a patient. Lepr. Rev. 38, 243.

KARAT, A. B. A., KARAT, S., JOB, C. K. and FURness, M. A. (1967). Acute exudative arthritis in leprosyrheumatoid-arthritis-like syndrome in association with erythema nodosum leprosum. Br. med. .J. iii, 770 .

MADRID congress (1953). Technical resolutions and classification. Int. .J. Lepr. 21, 504.

RIDLEY, D. S. (1960). A bacteriologic study of erythema nodosum leprosum. Int. .J. Lepr. 28, 254.

wolcotT, R. P. (1947). Erythema nodosum leprosum in leprosy. Int. .J. Lepr. 15, 380. 